\title{
Chacoan Road Systems as Products of Social Organization
}

Jason G. Bush

\begin{abstract}
The Chacoan road system is an understudied aspect of a very unique culture in New Mexico. The extensive roads present important evidence to the social structure of the Chaco people. A few theories have been presented about the reason for the roads, such as economic, administrative and religion. This paper argues that the roads were used for military purposes, because the roads provided quick access to all satellite townships in the region.
\end{abstract}

Research and documentation of North America's Chaco Canyon has long been of interest to the archaeological community, although the meaning behind various aspects of its architecture remains puzzling. Several facets of the Chacoan buildings, burials, and trade systems have been well examined, while certain features, such as the expansive roadway system, have not received much scholarly attention. The Chaco system, the overall network of buildings and roads dating to roughly 1200 B.C.E., was comprised of over a dozen great houses which serviced smaller settlements, each acting as a locus of cultural continuity. Each great house was then linked to the single large settlement of Pueblo Bonito, the center of the Chacoan sphere of influence. Much is understood about the villages and buildings themselves, however little is known about the complex road system connecting this network of pre-historical towns. The goal of this study is to explore various aspects of the 
Chacoan road system in order to understand and interpret the reason it existed. I will argue that the complex roadway system can only be understood when it is considered as a component of a larger social system. In order to facilitate this, I will briefly discuss the background of Chaco Canyon, the road system, and three main theoretical models of Chacoan social organization. I will then examine how each model relates to the function and use of prehistoric roadways. Finally, I will introduce my own hypothesis of Chacoan road development complimentary to the previous models.

\section{Background}

Chaco Canyon was encountered by early European explorers and since then has been a place of mystery and heritage for Native Americans, tourists and archaeologists alike. It has been a source of near constant archaeological study, beginning in the latter part of the nineteenth century until modern times." A large number of projects have been completed on Chaco Canyon, most notably the 1971 Chaco Project, which later served as the source for many papers in recent publications.

In order to understand the Chacoan social system, it is important to appreciate the environment in which this prehistoric society existed. Chaco Canyon is located in northwestern New Mexico, in the heart of the San Juan basin. This region south of Colorado is considered a barren wasteland. "With an average elevation of 1800 
meters and only 220 millimeters of annual rainfall, the vegetation is sparse. ${ }^{3}$ Furthermore, the area is comprised of predominantly flat land, aside from the odd mesa or gully, and is considered marginal for sustaining human occupation. ${ }^{4}$ It is in this barren land where the Anasazi, the Chaco peoples, rose from a common pueblo-dwelling people into a large-scale society. ${ }^{5}$ Beginning in 900 C.E., and continuing over the next 250 years, these people completed monumental structures including Pueblo Bonito, a D-shaped complex comprised of nearly 800 rooms reaching as high as four stories tall. ${ }^{6}$ Over a dozen similar great houses were built, spreading throughout the San Juan basin, each one a centre for several smaller villages.' As these towns and cities grew, they required more and more resources. Each great house required tens of thousands of large wooden roof beams, millions of pieces of worked sandstone, and complex irrigation systems. $^{8}$ Over time the population of the Chacoan network expanded rapidly, with the most recent and systematic projections at over 10,000 people. ${ }^{9}$ It should be noted that a very wide range of population estimates have been made, ranging from 1000 to 30000 individuals. $^{10}$ It is through the growth and expansion of Chaco society that the complex Chaco road system was developed, an extensive network connecting each settlement and its satellite villages to its cultural center. 


\section{Chacoan Roadways}

Overview

The Chaco Anasazi roadways represent a complex and confusing aspect of current archaeological study. Many theories exist on the origin and use of these roadways, ranging from economic, religious and political uses, to a composite of all systems." While the origins of these roads are unknown, they can still be studied as physical monuments of prehistory. The road systems begin at an organizational center point of Pueblo Bonito, and radiate out towards the larger satellite communities. Secondary communities, mentioned previously as great houses, acted as regional centers for systems of villages and hamlets. $^{12}$ In addition to connecting inter-canyon settlements there are also roads reaching out past the canyon walls. A total of seven main roads begin in Chaco canyon and expand into the San Juan basin. ${ }^{13}$ Each road was linked with a major center, which also connected outlier communities via secondary connections. ${ }^{14}$ These connections represent a large network of connected settlements, requiring road construction on a massive scale. Aerial surveys of the San Juan basin reveal a possible 640 kilometers of roadway. ${ }^{15}$ Only 160 kilometers are in the Chaco Canyon itself. $^{16}$ Some 55 kilometers of potential roadway has been verified at ground level. ${ }^{17}$ This web of roads reached well into the San Juan basin and connected over 100 villages to a central core. ${ }^{18}$ The large scale connections converging at a center point, common in 
this system, are indicative of multi community interaction. ${ }^{19}$

Roads or Trails

Before determining the function of any road, the fundamentals of the road system must be considered and understood. The San Juan basin contains large expanses of relatively flat easily traversable land, yet roadways were constructed. It is necessary to examine the differences between roads and trails when dealing with a society that lacks wheeled vehicles or pack animals. $^{20}$ Trails represent a worn path resulting from repeated use. $^{21}$ Roads are the result of active and intended construction. Archaeologist Thomas Motsinger suggests a model defining four key ways of differentiating between trail wear and road construction. First, constructed roadways should contain evidence of large scale planning. In the Chacoan system, roads were constructed in relatively straight lines with Pueblos later constructed along their routes..$^{22}$ This suggests the roadways were constructed first, according to predesigned blue prints of Pueblo development. Second, roadways should bear evidence of engineering. Chacoan roads are strikingly straight and linear in nature when compared to modern engineered roads. Third, roadways should exhibit markings of construction. ${ }^{23}$ The steps and ramps carved into sandstone mesas on the Chacoan roads fulfill this requirement. ${ }^{24}$ Fourth, Motsinger's model requires evidence of road maintenance. If the roadways were important enough to be constructed, they were 
certainly worthy of maintenance. This is apparent on the Chacoan highways because with constructed wooden berms line several road edges. ${ }^{25}$ High artifact concentrations along roadsides indicate cleaning and sweeping activities. According to Motsinger's model, the roads of the Anasazi Chaco fulfill all requirements of constructed roadways. These roads were not mere trails beaten into valley floors, but instead were engineered pathways linking townships of thousands of people. Each road represents countless hours of planning, construction and maintenance. Each required a considerable investment of labor and planning. This is important in appreciating the overall value of the Chaco roads to the Anasazi people.

\section{Structure}

The Chacoan roadways radiated out from the Pueblo Bonito into the San Juan basin. The Chaco road system has been neglected by scholars, resulting in little interest in the Chaco road system, which is monumental in its own right. Chaco roads are generally over nine meters across, with smaller branching roads just over a meter across. $^{26}$ These roads often drastically reduce in width upon encountering steep inclines, gullies or other natural obstacles. ${ }^{27}$ Examples of this can be found on the road connecting Pueblo Bonito to Pueblo Alto, which stretches over mesa tops and cliff edges. ${ }^{28}$ Several other routes with similar features have been discovered, and it has been suggested log ladders were employed to move up the largest of cliff faces. ${ }^{29}$ In addition to regions of wide 
roads and geographical adaptations, parts of the Chaco roadways were carved directly into the bedrock cleaving a linear path for an unknown use. ${ }^{30}$ When attempting to interpret the function and origins of the Chacoan roads, their immense nature must be appreciated. Clearly these roads were of importance to the Anasazi people.

\section{Models of Social Organization}

Current theories on the origins of Chaco road systems are rooted in the exploration of Anasazi social organization. It is accepted a society must exist before public works can be completed. Therefore, the result of social organization is apparent in its road system on some scale. It is this social organization that is often the subject of many journals and publications. ${ }^{31}$ In this section I will discuss three main models of Chacoan social structure, including a brief critique, followed by an explanation of that each models relationship to the roadway system.

Economic - Redistributive Model

\section{Overview}

The Redistributive Model of Chacoan social organization is a pervasive one. At its core this model suggests a centrally organized social system, acquiring and redistributing wealth across its realm of influence. One theory regarding the inception of this model, seen below, was proposed by the anthropologist Jeffery Altschul. ${ }^{32}$ In this model, increasing populations of Anasazi created a large aggregation of peoples who sought to maintain 
control over their core areas..$^{33}$ As populations increased, the core area established towns in and outside the Chaco Canyon in order to distribute the population. ${ }^{34} \mathrm{~A}$ distributive system centered on the great kiva, an elaborate ceremonial structure, developed in order to ensure the welfare of all. ${ }^{35}$ Such a system was highly adaptive to a constantly increasing population, while still maintaining social control and cohesion across space. In this system Pueblo Bonito acted as the central point of the redistribution system, which is also referred to as a corporate chiefdom. ${ }^{36}$ According to this concept, goods would have been acquired from the general population in order to facilitate public rituals, construction projects, and even transfer food during shortages." Chacoan society was based on a redistribution system of financial management, social integration, labor coordination and control. ${ }^{38}$

\section{Evidence}

While the hypothesis of the redistributive system seems plausible, there are many arguments presented both for and against it. In the Redistributive model, Pueblo Bonito was the center of the network. While the location of this city makes it a likely candidate as the economic centre, stronger evidence is found in its sheer size. Pueblo Bonito is a huge complex of multistory buildings, amounting to nearly 800 rooms. $^{39}$ Many of these larger rooms are thought to have been intended for storage of imported trade goods. ${ }^{40}$ This argument coincides with the idea that if Pueblo Bonito was the center of the system, 
archaeological evidence would indicate large amounts of imported goods useful in a redistributive society." Such evidence has been found during excavations of Pueblo Bonito, giving credit to the redistributive model. Archeological digs recovered large quantities of various import goods including turquoise materials, ceramics, projectile points, timber, and shells. ${ }^{42}$ The foreign origin of these materials also validates the redistributive model. The closest source of turquoise, over 200 kilometers to the east and sources of timber nearly 80 kilometers away, suggests that Pueblo Bonito was a storage point. ${ }^{43}$ Shells from the Pacific Ocean only serve to reinforce the importance of this notion. ${ }^{44}$ In addition, materials such as non-local chipped stone were brought into Pueblo Bonito from every cardinal direction. One example is obsidian, which has no known regional source. ${ }^{45}$ Finally, evidence of maize imported from two different locations has been found, both with sources exceeding a distance of 75 kilometers. ${ }^{46}$ According to anthropologist Timothy Earle, redistributive societies are often recognized by monumental construction and lack of prestige goods. ${ }^{47}$ The Chacoan System fits this model because it has both large buildings and large amounts of generalized trade goods.

\section{Critique}

The main critiques of this system involve the fundamental structure of the redistributive model and current archaeological evidence. First, Earle states that routine distribution of goods simply would not work. ${ }^{48}$ 
According to Earle, goods could not be transported to outlier settlements. Instead, it could only be paid to specialists involved with specific events or projects. ${ }^{49}$ Second, pink chert from the Chuska Mountains 80 kilometers west of Chaco Canyon has been found in some volume within Pueblo Bonito. ${ }^{50}$ However, there is also evidence that this material was deposited at Pueblo Alto, a neighboring settlement. ${ }^{51}$ More excavation is needed in outlaying settlements, but the previous evidence suggests that some goods were not distributed out of Chaco Canyon.

Roads in a redistributive model

In this system, roads fulfilled a single function of facilitating and expediting the movement of goods between settlements. These roads are said to be the product of corporate strategy linking communities and facilitating growing interaction between settlements. ${ }^{52}$ High levels of pottery from Chuska Mountains were representative of the daily movement of people and goods along a major road, suggesting similar high traffic between settlements. ${ }^{53}$ Evidence certainly indicates this is a plausible theory, but raises many questions. If the Chacoan roads were intended to be used for the movement of large quantity goods, the route should follow the path of least resistance across the countryside. Yet the Chaco roadways often intersect with large steep inclines and cliff faces requiring careful attention to travel. These do not seem to be ideal routes for a person carrying large amounts of stone. 
Furthermore, a CIS (Geographic Information System) study found that Chacoan roads deviate wildly from a calculated 'route of optimal costs' suggesting these roads were not used for large scale movement of goods. ${ }^{54}$ Support for this model is divided, but the Redistribution model is not a reliable explanation for the origin and function of the Chacoan road system.

Leadership - Central Administration Model

Overview

The Central Administration Model is a hierarchical system with a ruling entity presiding over a large population. The beginnings of this system may have been quite similar to the redistributive system. Altschul proposes the original Anasazi community was a large stable state threatened by the migration of peoples to its core area. ${ }^{55}$ The Anasazi responded by building large walled settlements on or near land ideal for food production. ${ }^{56}$ As populations grew, new villages were under the protection and influence of the central administration, sending food or goods to Pueblo Bonito as tribute.

\section{Evidence}

The Central Administrative Model suggests a highly organized administration oversaw the daily life of the Chacoan people. The evidence for this model is weak, with most supporting elements drawn from circumstantial fact. Certain aspects of the supporting arguments have validity. First, the Central Administration Model would require a core management center. Pueblo Bonito would 
have been the home of the elite, administration, and craft specialists, while the general populace occupied smaller outlier great houses and villages. ${ }^{57}$ Second, largescale work projects in Chaco Canyon and beyond are all indicators of a complex and highly functional administrative system. $^{58}$ Construction works, such as Pueblo Bonito, would require large amounts of stone to be worked, in addition to timber that would have to be sourced and transported. The roads themselves would require considerable planning and labour investment. Altschul states such construction projects were carried out on a continual basis throughout the eleventh and twelfth centuries. $^{59}$ These projects all represent the planning and coordination of a central administration, with each project based on a pre conceived plan. ${ }^{00}$

\section{Critique}

While the evidence in support of a central administration cannot be disproved, several aspects of this theory are weak. Most importantly, there is limited evidence of an elite or ruling class in Pueblo Bonito. Only one burial has been excavated which may represent the remains of an elite individual. ${ }^{61}$ Under the wooden floor of room 33 in Pueblo Bonito, archaeologists have uncovered human remains associated with quantities of turquoise and shell, considered to be prestige items. $^{62}$ In addition, several skeletons were uncovered on top of this burial perhaps representing sacrificial victims. ${ }^{63}$ Other than this site, there is no evidence of elite burials. Archaeologist Colin Renfrew, among others, states that the evidence of elite 
burials is not enough to constitute an argument for presence of leadership. ${ }^{64}$

Roads in an Administrative Model

In the Central Administrative Model, roads must be examined differently. The roads may have been used for trade between settlements; however, they may be a result of a highly organized central administration. They may be considered make-work projects used to subjugate, occupy and punish populations. Archaeologist Ben Nelson considered roads public works on the same scale as the pyramids or Mesoamerican ball courts. ${ }^{65}$ Each road represents coordinated labor and planning, all rooted in the organization of the administrative system. ${ }^{66}$ In this model the exact purpose of the Chacoan road system is difficult to determine. The roads indicate planning and large labor requirements, but they contain odd features. Assuming roads were built to link settlements, facilitate trade or even occupy populations, one would expect them to avoid natural obstacles. Yet, Chacoan roads often intersect cliff-face mesas. The complex nature of the Chacoan road system is only exacerbated when viewed within the confines of this model, and suggests a multi causal explanation for road construction.

Religion - Sacred Location Model

Overview

Renfrew proposed an alternative model for Chacoan organization, is known as Location of High Devotional 
Expression. ${ }^{67}$ It suggests that Pueblo Bonito and Chaco Canyon were important religious centers. Renfrew states LHDE sites are places where powerful belief systems may have motivated people to complete costly and intensive projects such as monumental construction. ${ }^{68}$ This concept may have some merit because of the inhospitable environment of Chaco Canyon for sustaining large populations. ${ }^{.9}$

\section{Evidence}

Evidence supporting this model has been well received among scholars. As mentioned previously, LHDE motivates populations to complete large building projects, which may explain the existence of Pueblo Bonito in an arid landscape. In this sense, Pueblo Bonito is similar to the Egyptian Pyramids as an area of ceremonial value. ${ }^{70}$ This is supported by the fact that smaller pueblo structures existed in the area of great houses before, during and after the construction of great houses." Archaeological evidence also supports the concept of Pueblo Bonito as a religious center, where valuable goods were deposited in a ritual manner. ${ }^{72}$ This serves to explain the existence of non-local materials found within the confines of the city. An example of this is in archaeological evidence regarding un-worked pink chert. The stone was quarried from the Chuska Mountains 80 kilometers to the east. ${ }^{73}$ This stone was then deposited into the trash mounds at great houses in combination with food and utilitarian property. This is important for several reasons. First, the pink chert was deposited into 
the mounds in an un-worked state. ${ }^{74}$ This suggests the stone was mined, transported and deposited in a ceremonial manner. Second, ample supply of local chert, quartz and other stone within 20 kilometers reinforces the ceremonial validity of the pink chert deposition. ${ }^{75}$ Excavations on trash mounds of the Pueblo Bonito also suggest ceremonial evidence. Strata analysis suggests that the chert and other materials were periodically placed, rather than discarded in daily waste. ${ }^{76}$ Other objects (such as intentionally smashed pottery and faunal remains deposited in a similar fashion) support periodic ritual activity. ${ }^{77}$

\section{Critique}

As the concept of Pueblo Bonito as a center of devotional expression is a relatively new concept, there are few publications questioning its validity compared to the other models. However, some questions have been raised. The main criticism of this model is the low representation of iconography within the Chacoan archaeological record. $^{78}$ If the Chacoan people were devoted to a belief system creating such monumental works, the same high devotion should be evident within artifacts recovered from the sites.

Roads in a Religious Model

In a society organized according to Renfrew's model, large scale construction such as Pueblo Bonito must be considered religious investments. This same concept must be applied to the monumental Chacoan Road 
system. All roads in the Chaco Canyon and beyond lead back to Pueblo Bonito. In the context of this model, roads can be viewed as symbolic approaches to the religious centre of the universe. ${ }^{79}$ Religious inspiration would explain the linear nature of the roads as well as the measures to continue construction over high mesas and sheer cliff walls. Roads carved into bedrock only serve to reinforce that religion may have played a role in Chacoan road construction. ${ }^{80}$

\section{Militia Highways}

\section{Overview}

Each of the previous models for Chacoan organization have presented possible cases for the development and function of Chacoan roadways, opening the door to many questions. I propose Chacoan roadways were partly developed as a form of military defense. This model is not intended as a replacement for the previous models of social organization, but rather a complimentary concept that explains various factors of road construction and layout. The Chacoan interaction sphere was over 30,000 - 150,000 square kilometers and was populated by as many as 30,000 individuals.. ${ }^{81}$ This large scale would likely have at least a minimal military presence, yet this topic is rarely discussed in many published papers. The reason for this is certainly complex, but it likely has to do with public relations, and that many Native groups are unwilling or reluctant to acknowledge scholarly evidence of warfare. ${ }^{22}$ This has gone so far as to cause investigators to label caches of 
wooden swords as digging sticks, when in reality they are highly polished hard oak implements with no evidence of digging marks. ${ }^{83}$ In this section, I argue for the presence of a military society and its impact on Chacoan road use and development.

Evidence of warfare - Physical

As with all hypotheses in archaeology, material evidence must be examined in order to validate or falsify a concept. Until recently, archaeological evidence supporting Chacoan conflict has been left out of published research. For example, evidence of disrespected skeletal remains found in many kivas (proposed ceremonial centers) in Chaco canyon are rarely mentioned..$^{84}$ In addition to these skeletal remains, several other pieces of evidence serve to expose concepts of Anasazi conflict. Skeletal material recovered from various sites include a human vertebrae perforated by projectile point and burned rooms containing skeletons with cranial markings indication scalping. ${ }^{85}$ Large wooden swords and shields have been recovered, in addition to rock and kiva paintings of Anasazi soldiers in formation. ${ }^{86}$ The examples mentioned are only a portion of physical evidence that shed light on Chacoan violence, a topic well covered in the Steven LeBlanc's Prehistoric Warfare in the Southwest. ${ }^{87}$

Evidence of warfare - Linguistic and Historical While linguistic evidence of warfare can never be proven in the same respect as physical evidence, it is a strong 
indicator of past events. Linguistic evidence is found in the vocabulary of the Navajo language. Evidence indicates that these peoples were hunter gathers when they arrived in the plains region, not far from Chaco Canyon. $^{88}$ While the date of their arrival is a debated topic, linguistic evidence certainly links the Navajo with the Anasazi. The most striking linguistic link is found in the words "corn" and "enemy". In the Navajo language, the word for corn is "Anna bidda" meaning "enemies' food". ${ }^{\text {s } ~ I n ~ a d d i t i o n ~ t o ~ l i n g u i s t i c ~ e v i d e n c e, ~ S p a n i s h ~}$ historical records mention a Spanish alliance with pueblo dwelling people fighting against raiders from the plains, who even then were considered long time traditional enemies..$^{90}$

\section{Military use of roads}

Previous discussion, suggests violent contact between the Chacoan people and their neighbors. This violence, and the presence of warriers, indicated by rock paintings and physical evidence, introduces a new concept in Chacoan road utilization. I propose these roads were in part used for the rapid deployment of troops, and the assertion of dominance over regions connected by roadways. A direct comparison can be drawn between Chaco Canyon and La Quemada, Mexico, two prehistoric city/road systems linked together by a turquoise trade system. ${ }^{91}$ Both sites contain road systems implying boundaries, and Ben Nelson asserts that the La Quemeda roads represent strong military organization easily mobilized against military threats. ${ }^{92}$ Several aspects of the Chacoan road 
system seem to support this military concept. Many Chacoan villages are linked by line of sight, some with mesa top fortifications as an extra line of defense. ${ }^{93}$ Roads linking these communities are not cost optimal but instead take the shortest possible route between settlements. Each road sacrifices energy output and construction cost to maintain the shortest distance between any two places. Roads such as these would allow for rapid deployment of troops between settlements as well as serving as a constant indicator of Chacoan territory. While the concept of Chacoan warfare has been discussed by Steven LeBlanc and others, the paradigm has yet to be applied to some architectural features of the Chacoan landscape. Keeping in mind the presence of a military or policing system, it is easy to understand the function and use of the complex road system.

\section{Conclusion}

In this paper I have discussed many paradigms regarding the origins and function of the Chacoan road system. Many concepts have been introduced over the course of archaeological study on the Anasazi homeland, each with potential validities evidenced through artifactual remains. These concepts have then been utilized to hypothesize on origins and daily usage of the expanse of roadways found in the Chaco Canyon system. However, it is important to realize in this age of public relations, repatriation and historical sensitivity, that it is indeed possible that the desire to remain sensitive to aboriginal 
interests can negatively impact scholarly study. While it is unlikely that scholars actively overlook evidence of indigenous warfare, we must remember that these concepts may be left out of publication in an effort to remain respectful of existing native groups. The overall result may in turn cause concepts and paradigms to be presented that do not dutifully account for all aspects of a culture history. This concept is vitally important for the understanding of the expansive and perplexing Chacoan road system, the origins and use of which remain highly contentious. While these roads may not have been used solely for conflict related activities, it would be judicious to respect them as a potential tool for military operations.

\footnotetext{
${ }^{1}$ Catherine M. Cameron, H. Wolcott Toll, "Deciphering the Organization of Production in Chaco Canyon," American Antiquity 66 (200I): 7.

2 Thomas C. Windes, Peter J. McKenna, "Going Against the Grain: Wood Production in Chacoan Society," American Antiquity 66 (200I): I 2 I.

${ }_{3}^{3}$ Julio L. Betancourt, Jeffery S. Dean, Herbert M. Hull, "Prehistoric Longdistance Transport of Construction Beams, Chaco Canyon, New Mexico," American Antiquity, 5 I (1986): 370.

${ }^{4}$ Windes et al, Against the Grain I2I.

${ }^{5}$ Steven A. LeBlanc, Prehistoric Warfare in the American Southwest, (Salt Lake City: University of Utah Press, 1999), 120.

${ }^{6}$ Cameron et al, Deciphering, 6

${ }^{7}$ Ibid., 5,6.

${ }^{8}$ Larry Benson, Linda Cordell, Kirk Vincent, Howard Taylor, John Stein, G. Lang Farmer, Kiyoto Futa, "Ancient Maze from Chacoan Great Houses: Where was it Grown," Proceedings of the National Academy of Sciences of the United States of America 100 (2008): I3I.

${ }^{9}$ Ben A. Nelson, "Complexity, Hierarcy, and Scale: A Controlled Comparison between Chaco Canyon, New Mexico, and La Quemada, Zacatecas," American Antiquity 60 (1995): 600.

${ }^{10}$ Cameron et al, Deciphering, 8.

${ }^{11}$ John Kanter, “Ancient Roads and Modern Mapping," Expedition 39.3
} (1997): 49 
${ }^{12}$ Nelson, Complexity, 600.

${ }^{13}$ R. Gwinn, Vivian, The Chacoan Prehistory of the San Juan Basin, (San Diego: Academic Press, 1990), 318.

${ }^{14}$ Ibid.

${ }^{15}$ Ibid.

${ }^{16}$ Ibid.

${ }^{17}$ lbid.

${ }^{18}$ Nelson, Complexity, 600.

${ }^{19}$ Ibid, 605.

${ }^{20}$ Kanter, Ancient Roads, 49.

${ }^{21}$ Thomas n. Motsinger, "Hohokam Roads at Snaketown, Arizona," Journal of Field Archaeology 25 (1998): 89.

22 Ibid.

${ }^{23}$ lbid.

${ }^{24}$ Ibid.

${ }^{25}$ Ibid.

${ }^{26}$ Vivian, Chacoan Prehistory, 323.

${ }^{27}$ Ibid.

${ }^{28}$ Ibid., 324.

${ }^{29}$ lbid.

${ }^{30}$ Ibid., 323.

${ }^{31}$ Colin Renfrew, "Production and Consumption in a Sacred Economy:

The Material Correlates of High Devotional Expression at Chaco Canyon," American Antiquity 55 (200I); Catherine M. Cameron, "Pink Chert, Projectile Points, and the Chacoan Regional System," American Antiquity 66 (200I); Wolcott H. Toll, "Making and Breaking Pots in the Chaco World," American Antiquity 66 (200I); Wolcott H. Toll, "Making and Breaking Pots in the Chaco World," American Antiquity 66 (200I); Timothy Earle, "Economic Support of Chaco Canyon Society," American Antiquity 66 (200I).

${ }^{32}$ Jeffery H. Altschul, "The development of the Chacoan Interaction Sphere," Journal of Anthropological Research (1978).

33 lbid, 128.

${ }^{34}$ Ibid.

${ }^{35}$ lbid.

${ }^{36}$ Cameron, Pink Chert, 94; Cameron et al, Deciphering, 10.

${ }^{37}$ lbid.

${ }^{38}$ Earle, Economic Support, 29.

${ }^{39}$ Cameron et al, Deciphering, 6.

${ }^{40}$ Ibid.

${ }^{41}$ Cameron, Pink Chert, 94.

${ }^{42}$ Cameron et al, Deciphering, 6.

${ }^{43}$ Ibid., 10.

${ }^{44}$ Ibid.

${ }^{45}$ Cameron, Pink Chert, 84.

${ }^{46}$ Benson et al, Ancient Maze, 100.

${ }^{47}$ Earle, Economic Support, 26.

${ }^{48}$ Cameron, Pink Chert, 94.

49 Ibid.

${ }^{50}$ lbid., 80.

${ }^{51}$ Ibid., 90. 
${ }^{52}$ Cameron et al, Deciphering, I0; Vivian, Chacoan Prehistory, 318.

53 Toll, Breaking Pots, III.

${ }^{54}$ Kanter, Ancient Roads, 49; Atlschul, Chacoan Interaction, I 37.

${ }^{55}$ Atlschul, Chacoan Interaction, 137.

${ }^{56}$ Ibid.

${ }^{57}$ Renfrew, Production and Consumption, 16.

${ }^{58}$ Atlschul, Chacoan Interaction, 117.

${ }^{59}$ Ibid.

${ }^{60}$ Ibid.

${ }^{61}$ Nelson, Complexity, 612.

${ }^{62}$ Ibid.

${ }^{63}$ Ibid.

${ }^{64}$ Renfrew, Production and Consumption, 17.

${ }^{65}$ Nelson, Complexity, 6II.

${ }^{66}$ Ibid.

${ }^{67}$ Renfrew, Production and Consumption, 14.

${ }^{68}$ Ibid., 18.

${ }^{69}$ lbid., 7.

${ }^{70}$ lbid., 18.

${ }^{71}$ Cameron et al, Deciphering, 10.

${ }^{72}$ Ibid.

${ }^{73}$ Cameron, Pink Chert, 80.

${ }^{74}$ Ibid.

75 lbid., 8I.

${ }^{76}$ lbid., 93.

${ }^{77}$ Ibid.

${ }^{78}$ Renfrew, Production and Consumption, 17.

${ }^{79}$ Ibid., 19.

${ }^{80}$ Vivian, Chacoan Prehistory, 322.

${ }^{81}$ Cameron, Pink Chert, 6, 8.

${ }^{82}$ Richard J. Chacon, Ruben G. Mendoza, North American Indigenous Warfare and Ritual Violence, (Tuscon: University of Arizona Press, 2007): 225.

${ }^{83}$ LeBlanc, Prehistoric Warfare, 98- 178.

84 LeBlanc, Prehistoric Warfare, 178.

85 Cameron et al, Deciphering, 86; Vivian, Chacoan Prehistory, II 5.

86 LeBlanc, Prehistoric Warfare, 98, 108.

87 LeBlanc, Prehistoric Warfare.

88 Hoxie, Frederick E. ( 1996), Encyclopedia of North American Indians, (Boston: Houghton Mifflin Canada), 425.

89 Hoxie, North American Indians, 425.

90 Vivian, Chacoan Prehistory, 229.

91 Nelson, Complexity, 6II.

$92 \mathrm{lbid}$.

93 LeBlanc, Prehistoric Warfare, 66, 72. 